\title{
Plasma Somatostatin 28 Increases in Response to Feeding in Man
}

\author{
K. S. Polonsky, S. E. Shoelson, and H. M. Docherty, Department of Medicine, \\ The University of Chicago, Pritzker School of Medicine, \\ Chicago, Illinois 60637
}

\begin{abstract}
A B S TR A C T Tissue somatostatin-like immunoreactivity (SLI) consists of a number of molecular species including the cyclic tetradecapeptide or SRIF, an Nterminally extended form of SRIF termed somatostatin-28, as well as larger precursor peptides. The function and nature of circulating SLI is not well understood. In this report, we describe techniques for the definition of the components of plasma SLI in normal human plasma. Plasma SLI measured after gel filtration on Bio-gel P-6 columns was found to consist of from 1-3 peaks. The void volume peak was present in greatest concentration $(34.2 \pm 8.9 \mathrm{pg} / \mathrm{ml})$ and did not increase in response to a mixed meal. Very low levels of two additional peaks of SLI activity were found. To further characterize these peaks, $10-\mathrm{ml}$ plasma samples were extracted and concentrated on octadecylsilyl silica (C-18) cartridges with subsequent fractionation on Bio-gel P-6 columns. The two peaks that coeluted with synthetic SRIF and S-28 markers, respectively, were present in concentrations of $5.4 \pm 1.4$ and $4.8 \pm 1.9$ $\mathrm{pg} / \mathrm{ml}$ in fasting plasma. In response to a mixed meal, the $\mathrm{SLI}^{14}$ peak doubled $(12.9 \pm 2.4 \mathrm{pg} / \mathrm{ml})$ while the $\mathrm{SLI}^{28}$ peak increased to $29.9 \pm 7.2 \mathrm{pg} / \mathrm{ml}$ at $120 \mathrm{~min}$. These results provide evidence that $\mathrm{S}-28$ circulates in human plasma and its increase after feeding is consistent with a possible biological role for this peptide.
\end{abstract}

\section{INTRODUCTION}

Recent studies have focused on the distribution of and relationship between the various molecular forms of

Dr. Polonsky is the recipient of the Solomon A. Berson Research and Development Award of the American Diabetes Association. Address correspondence to Dr. Polonsky.

Received for publication 29 December 1982 and in revised form 23 February 1983. somatostatin (1-5). Thus the cyclic tetradecapeptide somatostatin (SRIF) ${ }^{1}$ initially identified in the hypothalamus is also present in other areas of the brain, the pancreas and gastrointestinal tract (3). The 28 amino acid form of somatostatin (S-28), which consists of SRIF with an $\mathrm{NH}_{2}$ terminal extension, is the predominant form of somatostatin in the intestinal mucosa but is also found in the hypothalamus and pancreas (2). It has also been demonstrated that cultured hypothalamic neurons are capable of synthesizing a 15,000mol wt form of somatostatin-like immunoreactivity (SLI) in addition to SRIF and S-28 (5). The 15,000 mol wt SLI is involved in two potential biosynthetic pathways leading to SRIF; either directly or via S-28 as an intermediate.

Circulating forms of both S-28 and SRIF have been identified in the portal vein of rats by Patel et al. (2) and we have made similar observations in the portal and peripheral circulation of rats and dogs (6). S-28 has not been previously identified in human plasma and its physiological function remains uncertain. This study was therefore undertaken to determine if S-28 could be detected in human plasma and to define the responses of plasma SLI component fractions following ingestion of a mixed meal.

\section{METHODS}

Subjects. Experiments were performed in five healthy human volunteers (age $28.6 \pm 2.5 \mathrm{yr}$ ) who were all within $110 \%$ of ideal body wt. Written informed consent was obtained and the study was approved by the Clinical Investigation Committee of the University of Chicago. After an

\footnotetext{
${ }^{1}$ Abbreviations used in this paper: SLI, somatostatin-like immunoreactivity; SRIF, cyclic tetradecapeptide somatostatin; TFA, trifluoroacetic acid.
} 
overnight fast peripheral venous samples for the measurement of plasma SLI were drawn into chilled tubes containing Trasylol $(500 \mathrm{KIU} / \mathrm{ml})$ and EDTA $(1.2 \mathrm{mg} / \mathrm{ml})$. Each subject then consumed a mixed meal consisting of $710 \mathrm{cal}$ made of $94.6 \mathrm{~g}$ carbohydrate, $26 \mathrm{~g}$ protein, and $25.2 \mathrm{~g}$ fat (Ensure plus, Ross Laboratories, Columbus, $\mathrm{OH}$ ). Postmeal samples were obtained at 30 -min intervals for a total of $180 \mathrm{~min}$. Plasma was separated immediately and stored at $-20^{\circ} \mathrm{C}$ until assayed.

Assays. Plasma glucose was measured using a glucose analyzer (Yellow Springs Instrument Co., Yellow Springs, $\mathrm{OH})$. SLI was measured by radioimmunoassay in $0.1 \mathrm{M}$ sodium citrate buffer containing $0.1 \% \mathrm{BSA}$ and $0.2 \%$ sodium azide, pH 5.0 as previously described (6). The rabbit antibody, R3b (anti-SRIF thyroglobulin), which is directed against the central part of the SRIF molecule, was used in a final concentration of $1: 15,000 .{ }^{125} \mathrm{I}_{-} \mathrm{Tyr}^{1}$ SRIF was prepared by the Iodogen method (Pierce Chemical Co., Rockford, IL) and was purified on a Sephadex G-25 (fine) column $(1 \times 50 \mathrm{~cm})$. Final assay volume was $900 \mu \mathrm{l}$ and incubations were carried out for $72 \mathrm{~h}$. Charcoal was used to separate bound from free peptide. Synthetic SRIF (Bachem Chemicals, Torrance, CA) and S-28 (gifts of Dr. N. Ling and Dr. R. Guillemin, Salk Institute, San Diego, CA) were used as standards. Under these acid assay conditions, there was no degradation of labeled SRIF as assessed by immunoprecipitation and gel filtration chromatography. The sensitivity of the assay measured by the least amount of peptide causing significant displacement $(P<0.025)$ of ${ }^{125} \mathrm{I}-{\mathrm{T} y \mathrm{r}^{1}}^{1}$ SRIF was
$1 \mathrm{pg} /$ tube for SRIF and $4 \mathrm{pg} /$ tube for S-28. Interassay variation was $\pm 9.4 \%$ and intraassay variation was $\pm 6.7 \%$.

Gel chromatography. Gel chromatography of plasma was performed on Bio-gel P-6 columns $(1 \times 47 \mathrm{~cm})$ equilibrated in the assay buffer. 1-ml plasma samples from the fasting and 120 -min sampling times were applied to the columns. SLI was eluted under gravity at a flow rate of $0.1 \mathrm{ml} / \mathrm{min}$. Aliquots $(0.5 \mathrm{ml})$ were collected and the entire fraction assayed for its SLI content. Recovery of SRIF and S-28 standards added to the column was $>90 \%$. Recovery of total plasma SLI added to the columns was $96.2 \pm 9.1 \%(n=10)$.

Concentration of plasma. In view of the low levels of SLI components found in $1 \mathrm{ml}$ of plasma, additional aliquots of plasma drawn at the fasting and 120 min sampling times were concentrated in the following manner: $10 \mathrm{ml}$ plasma was diluted twofold with $1 \%$ trifluoroacetic acid (TFA). The mixture was passed through a reverse-phase octadecylsilyl silica (C-18) cartridge (Sep-pak, Waters Co., Inc., Milford, MA) to which the SLI adsorbed. The cartridge was rinsed with $5 \mathrm{ml} 1 \%$ TFA and the SLI was eluted with $1.5 \mathrm{ml}$ of a mixture of acetonitrile, water, and TFA (400:99:1). The extract was dried by rotary evaporation and reconstituted in $1 \mathrm{ml}$ assay buffer. SLI was then measured directly or after gel filtration chromatography.

Additional validation of the techniques for concentration and chromatographic separation of the plasma SLI components was performed as follows. (a) Increasing volumes (2, $4,6,8,10 \mathrm{ml}$ ) of the same plasma samples were extracted on C-18 cartridges. Total SLI content measured in each al-

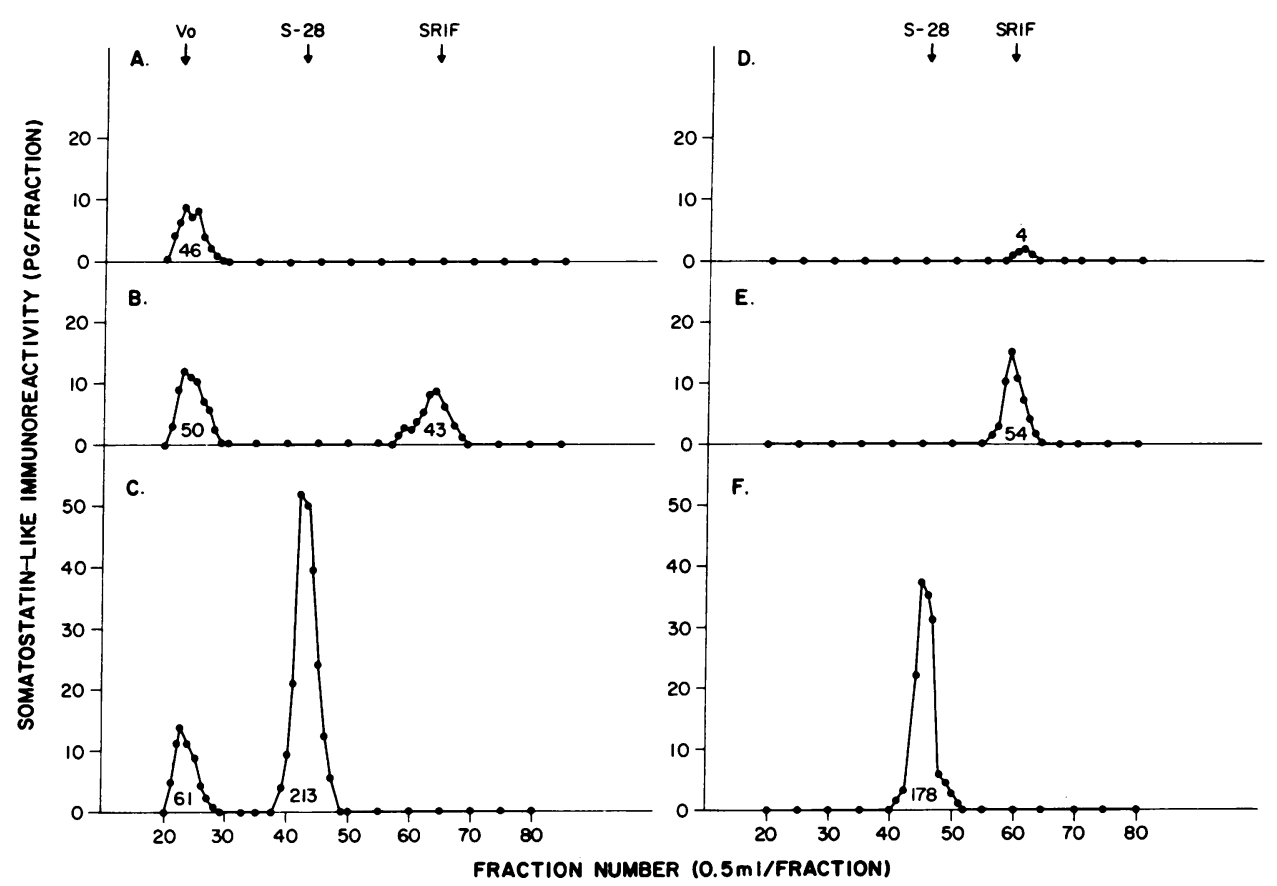

FIGURE 1 Recovery of SRIF and S-28 added to aliquots of a plasma sample: Profiles of SLI in panels $\mathrm{A}, \mathrm{B}$, and $\mathrm{C}$ were obtained after gel filtration of $1-\mathrm{ml}$ plasma samples on Bio-gel P6 columns. The profiles in panels $D, E$ and $F$ were obtained after $1-m l$ plasma samples were extracted on C-18 cartridges and the extract gel filtered on Bio-gel P-6 columns. 50 pg of SRIF was added to the plasma in experiments shown in panels B and E. 200 pg of S-28 was added to the plasma in experiments shown in panels $C$ and F. Columns were calibrated with synthetic S-28 and SRIF as shown by the arrows. 
iquot increased in proportion to the original volume of plasma extracted. Thus the concentration of SLI calculated as picograms per milliliter of plasma was independent of the initial volume of plasma used for the extraction procedure (coefficient of variation $\pm 6.7 \%$ ). (b) Known concentrations of SRIF and S-28 were added to plasma as shown in Fig. 1. $94 \pm 8.2 \%(n=5)$ of the SRIF and $96.2 \pm 9.8 \%(n=5)$ of S28 added were recovered following gel filtration of the plasma samples. When plasma was extracted on C-18 cartridges and then gel filtered, recovery of added SRIF and S-28 was $92.8 \pm 7.1 \%(n=5)$ and $83 \pm 4.0 \%(n=4)$, respectively (Fig. 1).

\section{RESULTS}

Total plasma SLI levels were measured in unextracted plasma before and after the mixed meal. In response to the meal, the fasting SLI concentration $(32.6 \pm 5.7$ $\mathrm{pg} / \mathrm{ml}$ ) increased in each subject reaching concentrations of $48.2 \pm 7.2,46.8 \pm 7.3,47.2 \pm 7.4,50.2 \pm 8.8$, $48 \pm 6.5$, and $41.8 \pm 5.4 \mathrm{pg} / \mathrm{ml}$ at successive $30-\mathrm{min}$ time points. The increase in plasma SLI was significant $(P<0.01)$ at each time $(30-180 \mathrm{~min})$.

Chromatography of 1-ml plasma samples on Bio-gel P-6 columns showed that the SLI eluted from the columns in three discrete peaks (Table I, and Fig. 2). A void volume SLI peak was measured in each subject; its concentration did not increase significantly after feeding. In the fasting state low levels of an inter- mediate sized peak that coeluted with synthetic S-28 $\left(\mathrm{SLI}^{28}\right)$ was present in one of the five subjects. However 120 min postprandially this peak was detectable in all subjects and increased in the subject in whom it had previously been detected. A low molecular weight peak that coeluted with synthetic SRIF (SLI ${ }^{14}$ ) was detected in one of the five subjects in the fasting sample and low concentrations of this peak appeared after the meal in each subject.

When 10-ml plasma samples were extracted on C18 cartridges and then chromatographed on Bio-gel P-6 columns the void volume peak was almost totally eliminated (Table I and Fig. 2). Two peaks, coeluting with S-28 $\left(\mathrm{SLI}^{28}\right)$ and SRIF $\left(\mathrm{SLI}^{14}\right)$ were present in both the fasting and postprandial samples. The concentration of $\mathrm{SLI}^{28}$ increased from a basal level of $48.4 \pm 19.1$ $\mathrm{pg} / 10 \mathrm{ml}$ to $299.4 \pm 71.8 \mathrm{pg} / 10 \mathrm{ml}(P<0.01)$ at 120 min after the meal stimulus. The $\mathrm{SLI}^{14}$ peak increased from a fasting concentration of $53.6 \pm 14.4 \mathrm{pg} / 10 \mathrm{ml}$ to $129 \pm 24.0 \mathrm{pg} / 10 \mathrm{ml}(P<0.005) 120 \mathrm{~min}$ postprandially.

\section{DISCUSSION}

The measurement of SLI in human plasma is difficult for a variety of reasons: (a) plasma SLI consists of heterogeneous components of different molecular size,

TABLE I

SLI Levels in Three Peaks from Plasma Drawn in the Fasting State and 120 min after a Mixed Meal in Five Normal Volunteers

\begin{tabular}{|c|c|c|c|c|c|c|c|}
\hline \multirow[b]{2}{*}{ Subject } & & \multicolumn{3}{|c|}{ A } & \multicolumn{3}{|c|}{ B } \\
\hline & & SLI $^{\mathrm{Vo}_{0}}$ & $\mathrm{SLI}^{28}$ & $\mathrm{SLI}^{14}$ & $\mathrm{SLI}^{\mathrm{Vo}^{\circ}}$ & $\mathrm{SLI}^{28}$ & $\mathrm{SLI}^{14}$ \\
\hline \multirow{2}{*}{1} & Fasting & 65 & 7 & 3 & 0.3 & 11.8 & 7.3 \\
\hline & Postmeal & 54 & 15 & 3 & 0.5 & 53.8 & 19.7 \\
\hline \multirow[t]{2}{*}{2} & Fasting & 40 & 0 & 0 & 0 & 3.3 & 8.6 \\
\hline & Postmeal & 47 & 14 & 5 & 0 & 33.4 & 16.7 \\
\hline \multirow[t]{2}{*}{3} & Fasting & 32 & 0 & 0 & 0 & 3.3 & 2.9 \\
\hline & Postmeal & 31 & 10 & 2 & 0 & 31.3 & 8.5 \\
\hline \multirow[t]{2}{*}{4} & Fasting & 20 & 0 & 0 & 0 & 5.4 & 7.0 \\
\hline & Postmeal & 24 & 11 & 1 & 0 & 19.9 & 12.6 \\
\hline \multirow[t]{2}{*}{5} & Fasting & 14 & 0 & 0 & 0 & 0.4 & 1.0 \\
\hline & Postmeal & 16 & 10 & 5 & 0.8 & 11.3 & 7.0 \\
\hline \multirow[t]{2}{*}{ Mean \pm SEM } & Fasting & $34.2 \pm 8.9$ & $1.4 \pm 1.4$ & $0.6 \pm 0.6$ & $0.1 \pm 0.1$ & $4.8 \pm 1.9$ & $5.4 \pm 1.4$ \\
\hline & Postmeal & $34.4 \pm 7.1$ & $12 \pm 1.0$ & $3.2 \pm 0.8$ & $0.3 \pm 0.2$ & $29.9 \pm 7.2$ & $12.9 \pm 2.4$ \\
\hline
\end{tabular}

Results are expressed as total SLI (picograms)/peak. The SLI levels in the SLI ${ }^{\mathrm{Vo}}$ and SLI ${ }^{14}$ peaks were read off an SRIF standard curve and the $\mathrm{SLI}^{28}$ levels were read off an S-28 standard curve. The values in panel A represent SLI content of each peak obtained after gel filtration of $1 \mathrm{ml}$ of plasma on Bio-gel P-6 columns. Recovery of total plasma SLI added to the columns was $96.2 \pm 9.1 \%(n=10)$. The values in panel B represent the SLI content of each peak obtained after extraction of $10 \mathrm{ml}$ of plasma on C-18 cartridges with subsequent gel filtration of the extract on Bio-gel P-6 columns. The value for the SLI content in each peak in panel B was divided by 10 to facilitate comparison with the values in panel $A$. 


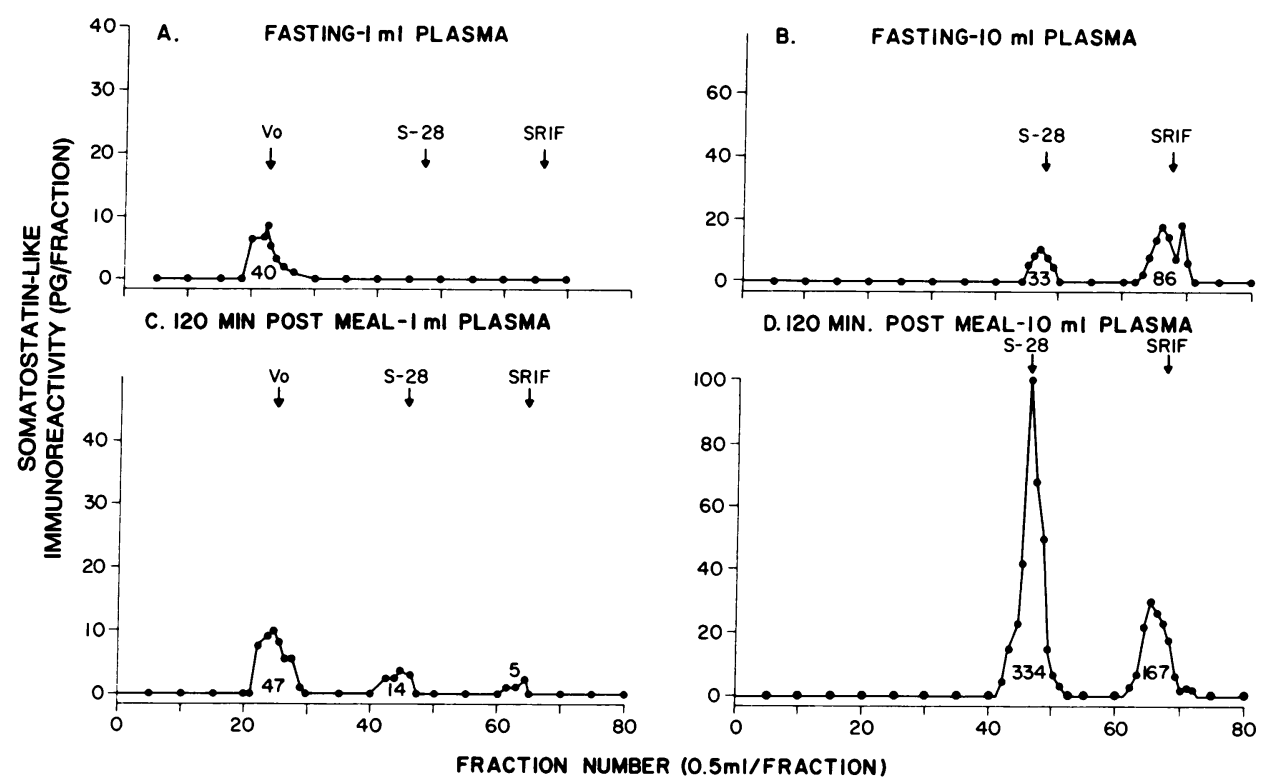

FIGURE 2 The effect of feeding on SLI components in human plasma: (subject 2) panels A and $C$ represent SLI profiles obtained after gel filtration of $1 \mathrm{ml}$ of plasma obtained in the fasting state and 120 min postmeal, respectively. Panels B and D represent the profiles of SLI in 10 $\mathrm{ml}$ of the same plasma samples, which were extracted on C-18 cartridges and then gel filtered.

each of which is present in very low concentration (7$9)$; (b) circulating somatostatin binding factors that interfere with the somatostatin assay, have been reported $(8,9)$ and $(c)$ proteolytic enzymes in plasma have been shown to degrade the SRIF tracer under certain conditions $(7,9,10)$. These methodological difficulties have resulted in significant controversy concerning the level and nature of circulating SLI. Thus while some investigators have described circulating SLI levels to be $<100 \mathrm{pg} / \mathrm{ml}$ in $\operatorname{man}(9-11)$, others have reported concentrations that are considerably higher $(7,12)$. Although most studies have indicated that the void volume peak of immunoreactivity is the predominant circulating SLI component (8, 9 ), Kronheim et al. (7) suggested that the lower molecular weight form is present in greatest concentration.

In the present studies we have utilized a variety of approaches to overcome the methodological problems associated with the radioimmunoassay of plasma SLI. Fortunately, the unusual binding characteristics of our antibody, R3b, permitted a sensitive radioimmunoassay to be performed at pH 5.0, under which conditions degradation of ${ }^{125} \mathrm{I}-\mathrm{Tyr}^{1}$-SRIF tracer is completely inhibited (12). The full characterization of plasma SLI requires its separation into its component peaks on gel columns. Thus gel filtration chromatography of 1-ml plasma samples showed the predominant circulating form of plasma SLI in both the fasting state and postprandially to be the void volume component, whose concentration $(34.2 \pm 8.9 \mathrm{pg} / \mathrm{ml})$ did not increase in response to feeding. The components of SLI that coelute with SRIF and S-28 were not consistently found in the fasting state by this technique, presumably due to their low levels and to the significant dilution factor inherent in the column separation procedure. Furthermore, the low levels of $\mathrm{SLI}^{28}(12 \pm 1.0 \mathrm{pg} / \mathrm{ml})$ and $\mathrm{SLI}^{14}(3.2 \pm 0.8 \mathrm{pg} / \mathrm{ml})$ present after feeding made accurate quantitation of these peaks difficult when whole plasma was separated on columns. We therefore concentrated $10 \mathrm{ml}$ plasma on C-18 cartridges. This allowed the measurement of very low concentrations of plasma SLI and facilitated accurate chromatographic separation of its various components. In addition it eliminated the void volume immunoreactivity, which is probably due to a cross-reacting protein unrelated to physiologically active somatostatin. The results of these experiments indicate that fasting plasma clearly contains both $\mathrm{SLI}^{28}(48.4 \pm 19.1 \mathrm{pg} / 10 \mathrm{ml})$ and $\mathrm{SLI}^{14}$ $(53.6 \pm 14.4 \mathrm{pg} / 10 \mathrm{ml})$. Furthermore, $120 \mathrm{~min}$ after feeding, the levels of $\mathrm{SLI}^{28}$ increased sixfold over base line to $299.4 \pm 71.8 \mathrm{pg} / 10 \mathrm{ml}$ and levels of $\mathrm{SLI}^{14}$ doubled to $129 \pm 24.0 \mathrm{pg} / 10 \mathrm{ml}$.

It is evident from Fig. 2 and Table $I$ that the total SLI level recovered in the $\mathrm{SLI}^{14}$ and $\mathrm{SLI}^{28}$ peaks after extraction of $10 \mathrm{ml}$ of plasma represents a $>10$-fold increase over the level in each of these peaks measured after gel filtration of $1 \mathrm{ml}$ of unextracted plasma. However, when known concentrations of SRIF and S-28 were added to plasma and then subjected to the same 
extraction procedure the recovery of these peptides was $92.8 \pm 7.1$ and $83 \pm 4 \%$, respectively. Furthermore, extraction of increasing volumes of aliquots of the same plasma resulted in a linear increase in the measured SLI levels (coefficient of variation, $\pm 6.7 \%$ ). Therefore, the apparent over-recovery of the $\mathrm{SLI}^{14}$ and $\mathrm{SLI}^{28}$ peaks obtained from $10-\mathrm{ml}$ samples in comparison to $1-\mathrm{ml}$ samples is probably related to dilution of SLI in the 1-ml samples below the sensitivity of the assay. Thus, in Fig. 2, panel $\mathrm{C}$, the peaks of $\mathrm{SLI}^{14}$ and $\mathrm{SLI}^{28}$ are narrow comprising only three to four column fractions after chromatography of $1 \mathrm{ml}$ of plasma. In contrast, as shown in panel D, the SLI in each of these peaks is above the detection limit of the assay in 8-10 column fractions after concentration and extraction of a 10-ml plasma sample.

The physiological significance of plasma SLI and its constituent components is at present uncertain. Zyznar et al. (11) reported that the total plasma SLI concentration increased from 8 to $20 \mathrm{pg} / \mathrm{ml}$ after feeding. Furthermore, they found that infusion of SRIF at a rate calculated to mimic this increase in plasma SLI had physiological effects resulting in suppression of plasma insulin and glucagon levels. In this study we have documented that in response to feeding there is an increase not only in the level of $\mathrm{SLI}^{14}$ but also a consistently greater increase in levels of circulating $\mathrm{SLI}^{28}$. In view of the fact that $\mathrm{S}-28$ is more active than SRIF in some biological systems (13), and since its plasma clearance rate is slower than that of SRIF (14), circulating $\mathrm{SLI}^{28}$ may constitute the major biologically active plasma SLI component. It has recently been suggested that S-28 is not merely a biosynthetic precursor of SRIF (5) but a physiologically distinct peptide. Thus S-28 has greater affinity for pituitary receptors than SRIF but a lower affinity for brain receptors (15). Furthermore, its tissue distribution in the central nervous system as well as the gastrointestinal tract and pancreas is discrete from that of SRIF (2). In the light of these differences between the two peptides it is important that future studies that aim to define the role of plasma SLI in normal physiological responses, as well as disease states, give due consideration to the relative contributions of the void volume, $\mathrm{SLI}^{14}$ and $\mathrm{SLI}^{28}$ peaks to total plasma SLI.

\section{ACKNOWLEDGMENTS}

The authors wish to thank Drs. Arthur Rubenstein and Jonathan Jaspan for invaluable advice and support.
This work was supported in part by the Diabetes Research and Training Center (AM-20595) and Clinical Research Center (RR-00055)

\section{REFERENCES}

1. Pradayrol, L., J. A. Chayvialle, M. Carlquist, and V. Mutt. 1978. Isolation of a porcine intestinal peptide with C terminal somatostatin. Biochem. Biophys. Res. Commun. 85: 701-704.

2. Patel, Y. C., T. W. Heatley, and C. Ling. 1981. Multiple forms of immunoreactive somatostatin: Comparison of distribution in neural and non-neural tissues and portal plasma of the rat. Endocrinology. 109: 1943-1969.

3. Patel, Y. C., and S. Reichlin. 1978. Somatostatin in hypothalamus, extrahypothalamic brain and peripheral tissues of the rat. Endocrinology. 102: 523-530.

4. Benoit, R., P. Bohlen, N. Ling, A. Briskin, F. Esch, P. Brazeau, S. Y. Ying, and R. Guillemin. 1982. Presence of somatostatin-28-(1-12) in hypothalamus and pancreas. Proc. Natl. Acad. Sci. USA. 79: 917-921.

5. Zing, H. H., and Y. C. Patel. 1982. Biosynthesis of immunoreactive somatostatin by hypothalamic neurons in culture. J. Clin. Invest. 70: 1101-1110.

6. Shoelson, S., K. Polonsky, H. Docherty, J. Jaspan, and A. Rubenstein. 1982. Evidence for the presence of somatostatin 28 in plasma. Diabetes. 31: 474-477.

7. Kronheim, S., M. Berelowitz, and B. Pimstone. 1978. The characterisation of somatostatin-like immunoreactivity in human serum. Diabetes. 27: 523-529.

8. Harris, V., J. M. Conlon, L. B. Srikant, K. McCorkle, V. Schusdziarra, E. Ipp, and R. H. Unger. 1978. Measurements of plasma somatostatin like immunoreactivity in plasma. Clin. Chim. Acta. 87: 275-283.

9. Mackes, K., M. Itoh, K. Greene, and J. Gerich. 1981. Radioimmunoassay of human plasma somatostatin. Diabetes. 30: 728-734.

10. Lundquist, C., S. Gustavsson, R. Elde, and A. Arimura. 1980. A radioimmunosorbent assay for plasma somatostatin. Clin. Chim. Acta. 101: 183-191.

11. Zyznar, E. S., A. O. Pietri, V. Harris, and R. H. Unger. 1981. Evidence for the hormonal status of somatostatin in man. Diabetes. 30: $883-886$.

12. Vinik, A. I., N. S. Levitt, B. L. Pimstone, and L. Wagner. 1981. Peripheral somatostatin-like immunoreactive responses to insulin hypoglycemia and a mixed meal in healthy subjects and in noninsulin dependent maturity onset diabetics. J. Clin. Endocrinol. Metab. 52: 330-336.

13. Brazeau, P., N. Ling, E. Esch, P. Bohlen, R. Benoit, and R. Guillemin. 1981. High biological activity of synthetic replicates of somatostatin 28 and somatostatin 25 . Reg. Peptides. 1: 255-264.

14. Polonsky, K., J. Jaspan, M. Berelowitz, W. Pugh, A. Moossa, and N. Ling. 1982. The in vivo metabolism of somatostatin 28: Possible relationship between diminished metabolism and enhanced biological action. Endocrinology. 111: 1698-1703.

15. Srikant, C. B., and Y. C. Patel. 1981. Receptor binding of somatostatin 28 is tissue specific. Nature (Lond.). 294: 259-260 